\title{
CARA PANDANG JURNALIS PEREMPUAN \\ DALAM RUANG PRIBADI
}

\author{
Diah Amelia \\ Program Studi Penerbitan, Jurusan Penerbitan, \\ Politeknik Negeri Media Kreatif Jakarta
}

\begin{abstract}
:
This research explores the Standpoint of women journalists in the magazine business and economics on the profession and also whether they have an understanding of journalism in a gender perspective. This study is a qualitative research strategy and case study data collecting technique through interview, observation and literature. Standpoint theory hold on women's experiences that will take them to have some understanding. This theory emphasizes the reciprocal relationship between communication behavior and attitudes. The results presented that women have a standpoint that journalists consider important the existence of gender awareness and sensitivity within him to be able to produce news that defending the interests of women in business and economics magazine. However, patriarchal and capitalist culture contained in the private and public areas are still holding their efforts.
\end{abstract}

Keywords: Journalists, Women, Standpoint

\section{PENDAHULUAN}

Jurnalisme adalah kegiatan menghimpun berita, mencari fakta dan melaporkan peristiwa. Kegiatan itu merupakan tugas yang dijalankan jurnalis dalam usaha memunculkan informasi berita bagi masyarakat melalui media cetak atau elektronik. Dengan begitu ada dua aspek penting dalam jurnalisme. Pertama jurnalis yang merupakan individu-individu yang bekerja, mencari, mengolah, mengedit dan menyiarkan informasi. Yang kedua adalah media massa (cetak dan elektronik) yaitu alat untuk menyebarkan informasi yang sudah dicari oleh jurnalis. Istilah pers jika dikaitkan dengan komunikasi (Djuroto, 2004) berarti: usaha percetakan atau penerbitan, usaha pengumpulan dan penyiaran berita, penyiaran berita melalui media massa cetak dan elektronik, orangorang yang bergerak dalam penyiaran berita, dan medium penyiaran berita yaitu media cetak dan elektronik. Di samping itu, ada juga yang mengartikan pers dalam arti sempit merupakan kegiatan komunikasi yang dilakukan dengan perantara barang cetakan dan pers 
dalam arti luas merupakan kegiatan komunikasi, baik yang dilakukan dengan barang cetakan maupun dengan media elektronik seperti radio, televisi maupun internet (Kusumaningrat \& Kusumaningrat, 2006). Jurnalis adalah mereka yang bekerja di lembaga pers, tetapi itu dengan pekerjaan yang spesifik, terkait dengan proses penggalian, penulisan, dan seluruh proses berita termasuk fotografer atau kameramen. Artinya pimpinan redaksi dan jajarannya yang boleh mengaku sebagai jurnalis dan berhak mendapat identitas keanggotaan dari organisasi jurnalistik, sedangkan orang pers yang bertugas di luar bidang pemberitaan, baik di media cetak maupun elektronik, tidak boleh mengaku sebagai jurnalis (Mondry, 2008: 17-18).

$$
\text { F. Fraser Bond }
$$
menyatakan bahwa 'Journalism ambraces all the forms in which and trough wich the news and moment on the news reach the public'. Roland E. Wolseley (1969) menjelaskan jurnalistik adalah proses pengumpulan, penulisan, penafsiran, proses dan penyebaran informasi umum yang secara sistematis dan dapat dipercaya untuk diterbitkan pada suratkabar, majalah, ataupun disiarkan di stasiun siaran. Sementara menurut UU Pers No.40/1999 tentang pers, wartawan adalah orang yang secara teratur melaksanakan kegiatan jurnalistik. Dengan demikian bisa disimpulkan bahwa jurnalisme adalah kegiatan yang berhubungan dengan proses mencari, mengolah, dan menyiarkan informasi kepada khayalak dan disebarkan melalui media massa baik itu cetak maupun elektronik. Menurut Ensiklopedi Indonesia, jurnalistik adalah bidang profesi yang mengusahakan penyajian informasi tentang kejadian dan atau kehidupan sehari-hari (pada hakikatnya dalam bentuk penerangan, penafsiran dan pengkajian) secara berkala, dengan menggunakan sarana-sarana penerbitan yang ada.

Bill Kovach dan Tom Rosenstiel (2001) dalam The Elements of Journalism merumuskan elemen dasar jurnalisme agar bisa 
dipercaya oleh masyarakat. Tujuan jurnalisme adalah menyampaikan informasi yang dibutuhkan masyarakat hingga mereka bisa leluasa dan mampu mengatur dirinya. Jurnalisme membantu masyarakat mengenali komunitasnya. Jurnalisme, dari realitas yang dilaporkannya, menciptakan bahasa bersama dan pengetahuan bersama. Sementara Leornard Downie JR dan Robert G. Kaiser mengingatkan perlu adanya pemahaman tentang good journalism, dimana profesi jurnalistik memiliki peranan penting dalam menggalang kebersamaan masyarakat khususnya di saat krisis. Melalui fakta-fakta, penjelasan dan ruang diskusi yang dapat membantu masyarakat mengatasi masalah yang tidak terduga kejadiannya (Santana, 2005: 4-5). Jurnalisme di abad ke-20, telah menancapkan status yang cukup berpengaruh sebagai sebuah profesi. Ada empat faktor penting yang dipegangnya yaitu: perkembangan keorganisasian dari pekerjaan jurnalis, kekhususan pendidikan jurnalis, pertumbuhan keilmuan dan berbagai tehnik dari komunikasi massa dan pertanggungjawaban sosial kerja jurnalis.

Dilihat dari sejarahnya, jurnalis, seperti profesi media lainnya merupakan dominasi lakilaki dan meskipun kondisi sekarang telah mulai berubah, masih ada bukti nyata tentang horizontal dan vertical segregation. Horizontal segregation merujuk pada cara industri media dan aturan-aturan yang berbeda didalamnya telah tersegmentasi dengan gender lines, dimana perempuan yang hanya terkosentrasi di bagian status bawah dari industri (seperti koran lokal atau majalah perempuan) dan jenis pekerjaan (adminstrasi dan pekerjaan pendukung). Vertical segregation adalah cara melihat bahwa meskipun pada bidang yang sama (seperti produksi di televisi), mereka cenderung memiliki peranan yang kecil dalam hirarki, sementara lakilaki mendominasi tingkat atas manajemen (Gill, 2007: 121). Diskriminasi, pelecehan seksual sampai dengan kekerasan terhadap jurnalis perempuan tidak bisa 
dilepaskan dari posisi perempuan dalam masyarakat. Menurut Tong (1989), masyarakat telanjur meyakini bahwa secara kodrati perempuan kurang pandai dan secara fisik lebih lemah dibandingkan laki-laki. Karena itu sebagian besar masyarakat masih percaya pada pembagian kerja secara seksual yang mensubordinasikan perempuan. Sedangkan sektor publik yang dicirikan sebagai sektor dinamis dan memiliki sumber kekuasaan pada berbagai sektor kehidupan yang mengendalikan perubahan sosial sebagai milik laki-laki. Sejumlah stereotipe pun lantas menempel pada perempuan dan laki-laki berdasarkan peran jenis kelamin itu. Ada semacam pemakluman bahwa perempuan adalah emosional, penakut, lemah dan laki-laki adalah sebaliknya.

Menurut UU Pers dijelaskan bahwa dalam melaksanakan profesinya jurnalis mendapat perlindungan hukum. Begitu juga pada Peraturan Dewan Pers Nomor 05/Peraturan-DP/IV/2008 tentang standar perlindungan profesi jurnalis yang memaparkan bahwa dalam menjalankan tugas jurnalistik, jurnalis dilindungi dari tindak kekerasan atau intimidasi oleh pihak manapun. Meskipun begitu UU Pers maupun peraturan Dewan cenderung tidak secara tegas membahas tentang larangan adanya diskriminasi, pelecehan ataupun kekerasan terhadap jurnalis perempuan. Inisiatif perlindungan terhadap jurnalis perempuan justru datang dari AJI (Aliansi Jurnalis Indonesia) yang membuat piagam kesetaraan gender ini meliputi persamaan kesempatan yang meliputi: akses terhadap pelatihan dan pilihan kerja yang didasarkan pada kemampuan individu atas pelatihan atau pilihan kerja atau posisi karir; akses yang sama terhadap bidang penugasan; peningkatan karir yang disesuaikan dengan faktor pengalaman, kemampuan, produktivitas dan prestasi kerja; imbalan atau remunerasi kerja yang sama. Selain itu, adanya persamaan kesempatan dalam: kondisi kerja, termasuk jam kerja, masa cuti, liburan tahunan dengan tunjangan, perlindungan kesehatan dan keamanan kerja, juga 
jaminan keamanan sosial pribadi. Yaitu rumahtangga, (jamsostek), serta fasilitas-fasilitas kehamilan dan mengurus anak. kesejahteraan dan keuntungan yang Menurut Pamela J. Shoemaker \& diberikan berkaitan dengan pemberian kerja; pelatihan kesetaraan gender, dan tidak adanya halangan dalam promosi untuk menduduki jabatan struktural (www.jurnalperempuan.com, 8 September 2005). Tapi pada kenyataannya, struktur kerja keredaksian justru masih menyerap nilai-nilai yang melemahkan posisi jurnalis perempuan sehingga amat mudah tergelincir untuk melakukan kekerasan ataupun diskriminasi berganda terhadap perempuan.

\section{METODE PENELITIAN}

Metode yang digunakan adalah penelitian kualitatif dengan studi pustaka, observasi, dan wawancara mendalam. Studi pustaka berfokus pada pemahaman dan pengertian tentang profesi jurnalistik. Observasi dan wawancara dilakukan untuk mengetahui pengalaman pribadi perempuan yang berprofesi sebagai jurnalis di majalah bisnis dan ekonomi. Membahas tentang mekanisme penyingkiran dalam area Stephen Reese (1996), ada beberapa faktor yang secara hirarkis dapat mempengaruhi isi media. Faktor tersebut secara sistematis adalah faktor individu, faktor rutinitas, faktor organisasi media, faktor ekstra media dan faktor ideologi. Dalam peneliti ini akan lebih difokuskan pada faktor pertama dan faktor kedua. Faktor individu merupakan garda paling depan dalam penentuan isi berita. Merupakan peranan individu-individu dalam proses produksi berita yang dipengaruhi berbagai faktor yang melekat pada individu, seperti latarbelakang sosial, ekonomi maupun politik para jurnalis perempuan. Faktor rutinitas media berkaitan dengan rutinitas yang biasa dilakukan media dalam mengolah berita. Setiap media memiliki kebijakkan pemberitaan dan pengolahan berita tersendiri yang disesuaikan dengan ciri khas media tersebut. Kebijakkan redaksional dijalankan dalam proses perencanaan, peliputan, penulisan 
hingga sampai tahap akhir dari rangkaian proses produksi.

\section{HASIL DAN PEMBAHASAN}

\section{Mekanisme Penyingkiran dalam}

\section{Area Pribadi}

Terjun ke dalam kerja kejurnalisan berarti kita masuk ke dalam dunia yang penuh tantangan. Perlu diingat, memutuskan diri untuk bekerja dalam dunia kejurnalisan, berarti seseorang sudah mempersiapkan dirinya untuk menghadapi segala resiko, tantangan dan hambatan serta kesulitan yang siap menghadang di depan. Kerja jurnalistik memang penuh dengan resiko. Anggapan ini memang tidak berlebihan. Bukankah sudah terlalu sering terdengar, banyak jurnalis yang mendapat tekanan serta menjadi korban kekerasan sejumlah orang akibat pemberitaannya dipandang telah merugikan mereka. Setiap jurnalis harus siap menghadapi tantangan-tantangan seperti itu, dan ketika dia mampu menghadapinya maka di situlah letak profesionalitas dari seorang jurnalis. Persoalannya apakah keluarga bisa menghadapi kondisi seperti itu.
Siapkah keluarga melihat anak atau isterinya bekerja dari pagi sampai malam, kelelahan dan kurang tidur ketika memburu memberita. Dan dapatkah jurnalis perempuan meninggalkan keluarga untuk mengejar informasi berita yang menarik dan terbaru. Lantas sejauh mana sikap orangtua, suami dan anak berpengaruh pada keberadaan mereka sebagai jurnalis.

\section{a. Orangtua}

Jika ingin memperhatikan adanya persetujuan atau ketidaksetujuan dari pihak orangtua terhadap profesi anaknya, maka kita bisa melihat adanya hubungan antara orangtua yang merupakan institusi sosial terkecil dari masyarakat dengan pandangan masyarakat. Sebab dalam berinteraksi dengan masyarakat sekitar, orangtua dapat mencermati pandangan masyarakat dan menjadi dasar bagi orangtua untuk memberikan persetujuan atau ketidaksetujuan atas pilihan anaknya. Sebagian besar informan mengakui bahwa orangtuanya tidak terlalu setuju ketika mereka memilih memasuki dunia jurnalistik. 
Meskipun banyak diantara mereka yang sebenarnya memberikan kebebasan kepada yang bersangkutan untuk memilih pekerjaan yang disukai. Sebab penolakkan itupun berbeda-beda. Seperti ada yang tidak setuju karena dunia jurnalistik dipandang bukan dunia yang cocok untuk seorang perempuan. Ataupun karena profesi jurnalisme dianggap tidak menjanjikan dari sisi ekonomi. Sementara yang lainnya, berkaitan dengan cara kerja jurnalis yang tidak teratur dan sering pulang malam.

Itu pula sebabnya yang membuat informan 4 diharapkan orangtuanya untuk mempunyai pekerjaan yang memberikan penghasilan dan jam kerja yang pasti. Ditambah dengan kondisi informan yang harus meninggalkan daerah tempat tinggalnya untuk bekerja di Jakarta. Dari awal ketika memutuskan menjadi jurnalis sampai sekarang, orangtua informan tidak mendukung. Mereka belum menerima pilihan informan untuk berprofesi sebagai jurnalis. Apalagi jika mengingat kedua orangtua dan kakaknya adalah seorang PNS, maka desakan untuk menjadi PNS semakin gencar.

"Mereka juga masih belum terima sebenarnya. Iya... karena mungkin, karena mereka PNS jadi safety player aja. Yang masih... carinya yang mapan aja gitu. Kalau PNS kan jauh lebih enak. Kalau jurnalis identik dengan yang kerjanya begitulah. Di Jakarta pula. Kalau PNS ya selayaknya orangtua pasti mikirnya ya udah pasti. Nggak ada PHK, kedua ada pensiun. Ketiga maksudnya aku cewek gitu kan. Cewek itu nanti mikirnya kalau berkeluarga harus bagi waktu untuk keluarga jauh lebih enak. $Y a$ udah. Terus, pertimbangannya itu. Tadinya mereka pingin aku balik ke Jawa. Cuman akunya sendiri masih, nanti dulu deh."

Ada juga yang awalnya tidak mendukung, namun kemudian setelah melihat jam kerjanya fleksibel akhirnya tidak melarang. Kecuali itu, mereka juga didukung pengetahuan tentang dunia jurnalisme. Pengetahuan tersebut bisa diperoleh secara langsung dari orang yang dikenal berprofesi sebagai jurnalis atau orang yang karena pekerjaannya berhubungan dengan dunia jurnalistik. Pilihan JP 6 untuk menjadi jurnalis awalnya tidak 
disetujui oleh orangtuanya karena profesi itu dianggap tidak cocok untuk seorang perempuan. Apalagi ketika kuliah, dia sempat magang di TV dan rupanya orangtua justru merasa tidak nyaman dengan pilihan anaknya itu. Melihat jam kerja yang tidak teratur itu membuat ibu informan menyatakan dengan tegas ketidaksetujuannya. Bahkan orangtua sempat meminta dia untuk pindah profesi. Meski demikian informan 6 tidak mundur dari profesinya dan memutuskan untuk pindah ke media cetak. Dengan harapan orangtua akan lebih merasa aman dan jam kerjanya tidak seketat media televisi.

"Gue ketika magang pas bulan puasa. Akhirnya nyokap gue, kamu bener mau kayak begini, ya udahlah ganti aja yang istilahnya standar, kayak di kantor dan duduk manis di meja. Dan itu buat nyokap gue jauh lebih nyaman buat anaknya. Gak harus kelilingkeliling naik mobil ke gedunggedung. Sebenarnya sih menentang, tapi sekarang gue pilih ekonomi mereka support. Oh ternyata fleksibel."

Ketidaksetujuan juga sempat dialami oleh JP 5. Bagi orangtuanya, ijazah ilmu akutansi komputer yang diraih olehnya lebih memberikan peluang pengembangan karier. Informan yang pada saat lulus SMA sempat menyatakan keinginannya memilih jurusan komunikasi, rupanya harus sedikit kecewa karena pilihannya itu ditentang orangtua. Pekerjaan sebagai akuntan bahkan sempat dilakukannya selama 3 tahun. Orangtua informan 5 tidak setuju bukan hanya karena ritme kerjanya saja, tetapi lebih ke profesi jurnalis yang dipandang tidak cocok bagi perempuan sebab jurnalis itu meliput sampai tidak kenal waktu.

"Sebenarnya ditentang sih dulu, dari SMA aku mau ambil komunikasi khususnya jurnalistik itu sempat ditentang, makanya gak jadi kuliah di sana. Khususnya ini kaitannya dengan perempuan, seperti saya kan masih tinggal di rumah orang tua, lebih karena waktu saya terlalu banyak habis di kantor sendiri. Terus memutuskan untuk ke sini orangtua udah ya sudah gak masalah. Dukung-dukung saja."

Sementara itu ada juga jurnalis perempuan yang merasakan dukungan penuh dari pihak keluarga. Orangtua yang memberikan persetujuan memang sejak awal sudah memberikan kebebasan bagi 
informan untuk memilih pekerjaan yang disukai. Dengan dorongan dari orangtua itu membuat para informan semakin percaya diri untuk menekuni bidang ini. Seperti JP 2 menunturkan, ketika menyatakan keinginannya memilih jurusan ilmu komunikasi dan menjadi jurnalis, rupanya masih dimengerti oleh orangtuanya. Kebetulan ada tetangganya yang berprofesi sebagai jurnalis. Sang Ayah yang gemar membaca merasa senang jika bisa terus up date informasi seperti itu. Bagi informan 2 orangtuanya memberikan kebebasan dan kepercayaan penuh pada dirinya untuk memilih profesi. Yang terpenting dia bisa bertanggungjawab atas pilihannya itu dan tidak merusak nama baik keluarga.

"Ketika bilang masuk komunikasi, mau jadi jurnalis, masih dimaklumi. Mungkin kali dia ngerasa kalau jadi jurnalis bagus juga kali $y a$, dia up date informasi. Tapi dia tidak katakan secara langsung. Orangtua saya sebenarnya sudah lihat irama kerja seperti itu. Dan tapi nggak masalah ya, karena mungkin tipe orangtua saya justru dalam tanda kutip tidak memperhatikan anak. Tapi maksud tidak memperhatikan anak, bukan berarti dia tidak memperhatiin. Tapi kasih kebebasan aja gitu loh. Orangtua saya tipe yang menanamkan value dari kecil. Yang penting kamu itu jangan bikin rusak nama keluarga. Yang penting kau tanggungjawab gitu. Dan itu sangat membantu sekali karier jadi jurnalis."

Hal yang sama juga dalami oleh JP 1. Latar belakang ayahnya yang seorang seniman, memberikan kesempatan terbuka bagi dia dan saudaranya untuk memilih profesi yang diinginkan. "Kita tidak pernah sekalipun dikekang keinginannya. Terserah loe mau jadi apa. Mereka nggak pernah mengatur ataupun membatasi gerak-gerik kita," ujarnya. Persetujuan juga didapatkan oleh informan 7. Bahkan orangtua informan 7 tidak memberikan respon apa-apa ketika anaknya memilih profesi menjadi jurnalis. "Nggak ada respon. Mungkin karena sebidang juga dengan jurusan aku. Jadi respon orangtua nggak pa-pa, nggak masalah," terang dia ketika ditanya pendapat orangtua. JP 3 juga tidak pernah mendapatkan pertentangan yang berarti ketika memilih menjadi jurnalis. "Keluarga setuju-setuju saja, 
mungkin complain soal pulang malam. Tapi selebihnya pekerjaan jurnalis sendiri dianggap cukup bergengsi meskipun gajinya kecil”.

\section{b. Rumahtangga, Suami dan Mengurus Anak}

Ketika memasuki dunia jurnalistik, semua jurnalis perempuan yang diwawancarai belum menikah. Karena itu persoalan yang dihadapi oleh sebagian besar mereka pada dasarnya sama. Setelah berkeluarga, persoalan pokok yang dihadapi jurnalis perempuan bersumber dari masalah waktu. Terutama manakala jurnalis perempuan dalam posisi sebagai isteri juga dituntut berperan ganda, persoalan waktu ini semakin mencuat pada saat tertentu. Misalnya ketika anak sakit atau pembantu pulang kampung sementara jurnalis perempuan harus mengerjakan tugas profesionalnya. Dalam hal ini kembali jurnalis perempuan merasa dipojokkan seolah harus memilih antara karier atau anak. Kondisi semacam itu membuat hal kecil bisa menjadi persoalan besar. Terlebih jika suami ataupun isteri bekerja, dan ketika pulang ada urusan kelurga yang belum selesai padahal keduanya sama-sama letih. Egoisme muncul, masing-masing berharap yang lain sukarela membereskan urusan itu. Dan tak jarang terjadi pada keadaan seperti inilah ego suami sebagai laki-laki muncul. Isteri dituntut bertanggungjawab atas urusan keluarga, karena berdasarkan budaya patriarki sektor domestik memang menjadi urusan isteri.

Sebenarnya berdasarkan pengakuan para jurnalis perempuan, kemungkinan persoalan semacam itu sudah dibicarakan sebelum menikah. Jurnalis perempuan mengungkapkan bahwa karakter pekerja jurnalis yang terkadang menuntut banyak waktu di lapangan dan hingga larut malam juga sudah dijelaskan. Suami atau pasangan hidup harusnya sudah dapat memahami kondisi itu. Gambaran demikian terungkap dari pengalaman JP 6 dan suaminya. Suami informan 6 sama-sama lulusan IISIP dan sudah mengetahui betul ritme bekerja jurnalis karena dia juga bekerja di lingkungan media sebagai design grafis. Sehingga informan mendapatkan dukungan 
penuh dari suaminya untuk berprofesi sebagai jurnalis.

Sementara itu JP 6 juga harus bisa meyakinkan mertuanya bahwa dia tetap bisa mengusrus anak meskipun dia bekerja.

"Basic-nya gue juga sama suami gue, dia mendukung banget. Walaupun mertua gue kalau bisa ke luar kota jangan dong kasihan. Sampai gue kalau pergi liputan itu, misalnya gue ke Lombok...ini anak loe kasihan. Tapi suami gue bilang, jalan...jalan...saja. Suami untungnya hampir kenal semua klien-klien mendukung karena pemikirannya lebih ke kualitas pertemuan bukan kuantitasnya".

Hal yang sama juga dialami oleh JP 2. Dia hampir tidak memiliki kesulitan berarti dalam menjalankan kehidupan rumahtangganya. Pertemuan dengan suaminya pada saat bersama-sama melakukan liputan dulu cukup disyukurinya. Suami yang bekerja di sebuah stasiun TV sudah sangat memahami kondisi pekerjaannya. Dari awal informan sudah sepakat dengan suaminya untuk tetap berprofesi sebagai jurnalis setelah menikah. Bahkan dia melihat anaknya menjadi lebih mandiri dan tidak tergantung pada dirinya.

"Nah itu menariknya justru, kalau anak sudah terbiasa dengan irama kerja yang seperti ini. Anak jadi sangat mandiri. Saya itu nggak pernah merasa punya masalah sama anak. Kalau orang lain, aduh repot $y a$, anak gue PR segala macam. Saya malahan kok nggak pernah merasa repot $y a$. Tapi kalau sore itu memang sudah diplot bahwa tidak akan ketemu ibu bapaknya. Jadi dia bisa ngerjain PR sendiri. Apalagi kalau sekarang anak saya sudah $\mathrm{SD}$, sudah bisa yahoo messenger, YM-an. Gak tuh... gak pernah ada masalah. Dan dia lebih mandiri kalau tidak ada ibunya. Dia sudah ngerjain PR jam berapa, harus mandi jam berapa, atau dia harus apa".

Informan 5 pun merasakan dukungan dari suami. Meskipun dia masih mengandalkan orangtuanya dalam mengurus anak, tapi suami tidak pernah mempermasalahkan itu. Apalagi mengingat kesulitannya untuk hadir pada acara-acara keluarga yang harus karena jadwal deadline, tidak membuat suami marah. Salah satu cara untuk mengatasi frekuensi pertemuan dengan anak adalah membawa serta 
anaknya ke tempat kerja pada waktu weekend.

"Nggak percaya nitipin anak sama pembantu masih gitu, jadi saya masih di orang tua. Yang mendukung suami saja kalau keluarga protes bahkan kadang weekend sabtu-minggu juga jarang ada waktu untuk misalnya disuruh ada acara keluarga, datang... jadi susah. Apalagi yang sudah berkeluarga, kalau keluarganya tidak mendukung ya, itu susah banget pasti, apalagi kalau punya anak kecil. Kadangkadang saya saja sampai bawa anak saya ke sini kalau hari Sabtu."

Sementara bagi informan yang belum menikah mereka juga memiliki pendapat tersendiri melihat teman-teman satu profesinya terkait dengan menikah dan anak. Seperti JP 3 yang melihat setelah berkeluarga, banyak jurnalis perempuan yang menjadi tidak maksimal mengejar prestasi. "Secara keseluruhan aku melihat teman-teman jurnalis jarang yang ambisius untuk jabatan atau posisi di kantor, terlebih setelah mereka menikah dan punya anak," ujarnya memberikan pandangan. Di sisi lain, JP 1 justru berpendapat kondisi dan lingkungan tempat kerjanya memberikan kenyamanan bagi jurnalis perempuan. Hal itu bisa dibuktikan dengan banyaknya jurnalis perempuan yang tetap bekerja meskipun sudah menikah dan punya anak. "That's way kenapa banyak mbak-mbak di kantorku betah. Di kantorku rata-rata nggak masalah. Rata-rata jurnalis perempuan di kantorku yang sudah lebih lama dariku, rata-rata sudah di atas 8 tahun. Dan mereka kadangkadang mereka suka bawa anak ke kantor. Apalagi kalau pembantu pulang," terangnya. Namun hal yang berbeda justru dirasakan informan 7 . Adanya kekhawatiran karena berprofesi sebagai jurnalis akan menyulitkannya untuk masuk ke jenjang pernikahan. Pengalamannya JP 7 karena tidak adanya pengertian mengenai profesi jurnalis, membuatnya berpikir ulang untuk menjalin hubungan. "Untuk masuk ke sana masih berpikir berapa kali, untuk masuk ke fase rumahtangga itu. Informan 7 melihat memang karena kita profesinya jurnalis akhirnya dia agak-agak mikir lagi. Mau dengan seseorang jurnalis yang kemana-mana ke sana kesini. Makanya karena alasan itu ... duluan 
yang bikin ya udah kita nggak usah lanjutin aja hubungan kita”.

\section{c. Pandangan Masyarakat terhadap Profesi}

Belum semua anggota masyarakat menerima kenyataan tentang perempuan yang berprofesi sebagai jurnalis. Bagaimana pandangan masyarakat tentang profesi mereka sebagai jurnalis, kebanyakan diperoleh jurnalis perempuan dari tetangga, kenalan atau ibu kost. Pandangan itu ada yang disampaikan secara langsung, atau tidak langsung semisal melalui orangtua. Pandangan masyarakat itu berkaitan dengan kenyataan bahwa jurnalis perempuan memiliki jam kerja yang tidak jelas, sering pulang malam dan jarang bersosialisasi dengan tetangga. Rasa heran juga muncul dari kerabat atau tetangga terhadap pola kerja para jurnalis perempuan. Khususnya terkait dengan seringnya informan pulang malam. JP 6 merasakan betul rasa keheranan itu. Bukan satu atau dua orang tetangga yang pernah bertanya tentang jam kerjanya di media. Dengan rutinitas berangkat dan pulang tidak terjadwal bahkan membuat para tetangga mempertanyakan apakah informan memang bekerja.

"Karena kan profesi jurnal di masyarakat umum kayaknya bukan profesi yang kelihatan karena kan kita bisa berangkat kapan saja, pulang kapan saja, jam-nya itu gak tentu jadi dianggap kayak gak kerja gitu. Sampai tetangga gue pada binggung, kerja nggak sih. Nggak meyakinkan gue kerja."

Selain sering pulang malam, rasa heran itu bisa juga tercetusnya takala jurnalis perempuan mendapat giliran sebagai tuan rumah untuk pertemuan ataupuan arisan ibu-ibu. Sebagaimana yang pernah dialami oleh JP 2. Akibat tugas, terpaksa dia sering tidak bisa hadir. Informan 2 mengaku memang mendengar ada yang mempertanyakan ketidakhadirannya di pertemuan atau acara arisan itu, sekaligus mempertanyakan mengapa tugasnya di kantor tidak bisa ditinggalkan. Tapi menurut informan, dia akan selalu berusaha untuk meluangkan waktu, berkontribusi dan menunjukkan sikap perduli terhadap lingkungan sehingga pada akhirnya 
tetangga menjadi memahami profesinya.

"Dan kompensasinya adalah kita tetap berperan di lingkungan. Jadi istilahnya saya memang sering pulang malam. Tapi kalau ada kegiatan di lingkungan yang saya bisa luangkan waktu, saya akan luangkan waktu saya. Jadi... sehingga tidak sama sekali cuek misalnya. Walaupun kadang-kadang misalnya arisan bulanan, kalau arisannya lagi deadline ya saya nggak bisa hadir. Tapi terus ketika ada waktu, saya meluangkan untuk ketemu ibuibu. Pada akhirnya mereka menghargai profesi saya kok. Misalnya kita punya kemampuan lebih untuk memberikan informasi atau apa, kita memang harus meluangkan ke lingkungan. Jadi lingkungan tidak menjudge kita.

Informan 1 bahkan merasakan pendapat negatif bahkan dari kuliah. Pada saat dia memilih jurusan ilmu komunikasi, sudah banyak kerabatnya yang mempertanyakan alasan di memilih jurusan itu dan ditambah dengan aktifitasnya pada pers kampus yang sering membuat dia pulang malam. Padahal JP 1 yakin jika jurnalis perempuan memiliki kemampuan beradaptasi, seharusnya tidak masalah memiliki pekerjaan yang memang tidak mengenal waktu kerja yang rutin.

"Waktu aku masuk komunikasi pernah disepelekan. Ada yang bilang JP 1 memangnya dia sanggup, kerja jadi jurnalis itu kan berat. Aku sama sekali tidak suka kata-kata itu. Meski dia bilang sama ibuku tapi aku mendengar. Itu sudah tindakan menyepelekan orang lain. Frame dia adalah karena aku perempuan. Ada pendapat masyarakat seperti itu".

Para jurnalis perempuan mengakui, faktor budaya masih berpengaruh kuat terhadap pandangan sebagian besar anggota masyarakat, yang menilai bahwa keluar rumah pada malam hari tidak pantas bagi perempuan, sekalipun demi pekerjaan.

\section{PENUTUP}

Persetujuan atas pilihan profesi sebagai jurnalis, tidak dengan sendirinya menghilangkan kekhawatiran orangtua atas keselamatan anak mereka yang bekerja sebagai jurnalis dan pada kesempatan tertentu harus bekerja hingga larut malam. Hal sebaliknya pun juga terjadi. Ketidaksetujuan tidak selalu disebabkan kekhawatiran. Ketidaksetujuan 
berdasarkan alasan rasional, atau ketidaksetujuan yang dibungkus dalam kekhawatiran, keduanya mengindikasikan bahwa sebagian orangtua memang masih memandang dunia jurnalistik tidak cocok dimasuki perempuan. Dengan demikian perlu kerja keras dan usaha dari jurnalis perempuan yang akhirnya bisa meyakinkan orangtuanya untuk bisa menerima profesi anaknya.

Jika ditarik ke kecenderungan yang lebih umum, persoalan yang dihadapi para jurnalis perempuan di rumah tangga masing-masing sebenarnya berkaitan dengan masih kuatnya budaya patriarki mempengaruhi pola pikir masyarakat dalam mensikapi posisi suami isteri. Di satu sisi, adanya keinginan kuat untuk memenuhi kebutuhan ekonomi menyebabkan isteri diperbolehkan bekerja. Di sisi lain, adanya keinginan yang sama kuat agar keluarga tidak terlantar, apalagi anak, menyebabkan tuntutan agar isteri tetap bertanggungjawab atas urusan domestik kembali muncul ke permukaan. Terutama manakala jurnalis perempuan dalam posisi sebagai isteri juga dituntut berperan ganda, persoalan waktu ini semakin mencuat pada saat tertentu. Misalnya ketika anak sakit atau pembantu pulang kampung sementara jurnalis perempuan harus mengerjakan tugas profesionalnya. Dalam hal ini kembali jurnalis perempuan merasa dipojokkan seolah harus memilih antara karier atau anak. Dengan kata lain, persoalan apakah tanggungjawab terhadap urusan domestik merupakan hak atau kewajiban bagi perempuan yang bekerja, sepenuhnya belum terselesaikan.

Dari penuturan mereka terungkap, bahwa penilaian seperti itu lebih berkaitan dengan ciri pekerjaan jurnalis yang penuh mobilitas dari suatu ke tempat lain, walau malam hari sekalipun. Dengan kata lain, menjadi jurnalis di mata kebanyakan masyarakat bukan merupakan pekerjaan yang cocok bagi perempuan. Mengenai pandangan sedemikian, kebanyakan jurnalis perempuan berpendapat bahwa mereka memang sulit merubah persepsi masyarakat. Bukan 
berarti mereka tidak memberikan perhatian yang tinggi terhadap lingkungan, namun kesibukan karena pekerjaan menyebabkan waktu untuk berinteraksi secara sosial di tengah masyarakat menjadi berkurang.

\section{DAFTAR PUSTAKA}

Buzzanell, P.M., Helen Sterk., and Lynn. H. Turner. (2004). Gender Applied Communication Contexts. USA: Sage Publications

Chambers, Deborah., Linda Steiner., and Carole Fleming. (2004). Women and Journalism. New York: Routledge

Gill, Rosalind. (2007). Gender and The Media. Cambridge, UK: Polity Press

Griffin, EM. (2006). A First Look At Communication Theory. New York: McGraw-Hill

Griffin, EM. (2006). A First Look At Communcation Theory. Sixth Edition. New York: McGraw-Hil.

Harstock,N. (1998). The Feminist Standpoint Revisited and Other Essays. Boulder CO : Westview Press.

Harding, Sandra. (1996). Whose Science ? Whose Knowledge ? Thinking from Women's Lives. New York: Cornell University Press.
J. Creedon, Pamela (ed). (1993). Women In Mass Communication. USA: Sage Publications

Krolokke, Charlotte and Anne S. Sorensen. (2006). Gender Communication: Theories and Analyses. USA: Sage Publications

Littlejohn, Stephen. (2002). Theories of Human Communication. New York: Wadsworth

Mondry. (2008). Pemahaman Teori dan Praktik Jurnalistik. Bogor: Penerbit Ghalia Indonesia

Nurudin. (2009). Jurnalisme Masa Kini. Jakarta: Rajawali Pers

Pacanowsky, ME., dan O’DonnellTrujillo.N (1990) Communication and Organizational cultures, In S.R. Corman, S.P. Banks, C.R. Bantz, \& M.E. Mayer (ed), Foundation of Organizational Communication: A Reader. New York: Longman.

Patton, Michael Quinn. (2002). Qualitative Research \& Evaluation Methods. Third Edition. London: Sage Publication.

Pawito. (2008). Penelitian Komunikasi Kualitatif. Yogyakarta : PT. LkiS Pelangi Aksara.

Poerwandari, Kristi. (2001). Pendekatan Kualitatif untuk 
Penelitian Perilaku Manusia. Jakarta : LPSP3 UI

Punch, F.Keith. (1998). Introducing to Social Research, Quantitative and Qualitative Approaches. London: Sage Publication.

Ross, Karen and Carolyn M. Byerly. (2004). Women and Media : International Perspectives. UK: Blackwell Publishing

Siregar, Ashadi., Rondang Pasaribu., dan Ismay Prihastuti. (1999). Media dan Gender : Perspektif Gender atas Industri Suratkabar Indonesia. Yogyakarta: LP3Y dan Ford Foundation.

Soemandoyo, Priyo. (1999). Wacana Gender dan Layar Televisi. Yogyakarta: LP3Y dan Ford Foundation.

Sunarto. (2000). Analisis Wacana Ideologi Gender Media Anak-
Anak. Semarang:

Mimbar dan Yayasan

Adikarya Ikapi serta

Ford Foundation.

West, Richard and Lynn H. Turner. (2007). Introducing Communication Theory : Analysis and Aplication. New York: McGraw-Hill.

Yin, K. Robert. (2002). Studi Kasus : Desain dan Metode. Jakarta : PT Rajagrafindo Persada.

\section{Jurnal dan Artikel}

Hee Kim, Kyung. (2006). Media, Culture and Society, Vol 28. London: Sage Publication.

Lachover, Elnat. (2005). Journalism, Vol. 6(3): 291-311. London: Sage Publication

Hardin, Maria and Erin Whiteside. Journalism, Vol. 10(5): 627646. London: Sage Publication 